Anales de Geografía de la Universidad Complutense

ISSN: 0211-9803

https://dx.doi.org/10.5209/aguc.79347

\title{
Ensanche de Barcelona. Una visión crítica de los remontes y añadidos en los edificios del "Quadrat D'Or"
}

\author{
Miriam-Hermi Zaar'; Manuel-Blas García Ávila² \\ Recibido: 16 de junio del 2021 / Enviado a evaluar: 20 de junio del 2020 / Aceptado: 10 de diciembre del 2021
}

Resumen. El Plan Cerdà para el Ensanche de Barcelona comprendió varias fases, en las que estuvo sometido a diferentes ordenanzas. Este proceso urbanístico influyó decisivamente en la morfología de los edificios que fueron construyéndose. El objetivo de este artículo es elaborar un análisis estético de los remontes y añadidos realizados en los edificios del Quadrat d'Or, su área central caracterizada por una arquitectura espléndida. Para ello examinamos 298 edificios y clasificamos las ampliaciones de sus fachadas, según patrones estéticos fundamentales, como la armonía del añadido respecto al edificio existente, el resultado de la aplicación de diseños que contrastan con la obra original, los añadidos semiocultos y los remontes impropios o antiestéticos. La metodología adoptada ha sido la agrupación de las fachadas afectadas en siete tipologías, ateniéndonos al resultado estético y a su presencia global e integral, esto es, clasificando las intervenciones en los edificios por su aspecto final.

Palabras clave: Ensanche de Barcelona; Quadrat d'Or; Remontes y Añadidos de edificios; Estética urbana; Alteración de Fachadas.

\section{[en] Ensanche of Barcelona. A crítical view of the lifts and additions in buildings in the "Quadrat d'Or"}

\begin{abstract}
The Cerdà's Plan for the Ensanche of Barcelona included several phases, in which ones it was subjected to different ordinances. This urban process had a decisive influence on the morphology of the buildings that were being built. The objective of this article is to elaborate an aesthetic analysis of the lifts and additions made in the buildings of the Quadrat d'Or, its central area characterized by splendid architecture. To do this, we examined 298 buildings and classified the enlargements of their facades, according to fundamental aesthetic patterns, such as the harmony of the addition with the existing building, the result of the application of designs that contrast with the original building, the semi-hidden additions and the improper lifts or unsightly. The methodology adopted has been the grouping of the affected facades into seven typologies, taking into account the aesthetic result and their global and integral presence, that is, classifying the interventions in the buildings by their final appearance.
\end{abstract}

Keywords: Ensanche of Barcelona; Quadrat d'Or; Building lifts and additions; Urban aesthetics; Alteration of facades.

1 Universidad de Barcelona (España).

E-mail: miriamzaar@gmail.com

2 E-mail: manuelblasg@gmail.com 


\section{[fr] Ensanche de Barcelone. Une vision critique sur les remontages et les ajouts aux bâtiments du "Quadrat d'Or"}

Résumé. Le Plan Cerdà pour l'Ensanche de Barcelone comprenait plusieurs phases, dans lesquelles il était soumis à différentes ordonnances. Ce processus d'urbanisme a eu une influence décisive sur la morphologie des bâtiments en construction. L'objectif de cet article est d'élaborer une analyse esthétique des remontages et des ajouts réalisés dans les bâtiments du Quadrat d'Or, sa zone centrale caractérisée par une architecture splendide. Pour ce faire, nous avons examiné 298 bâtiments et classé les agrandissements de leurs façades, selon des patrons esthétiques fondamentaux, tels que l'harmonie de l'ajout avec le bâtiment existant, le résultat de l'application de conceptions qui contrastent avec l'œuvre originale, les ajouts inappropriées, inesthétiques ou les semi-cachés. La méthodologie adoptée a été le regroupement des façades affectées en sept typologies, en tenant compte du résultat esthétique et de leur présence globale et intégrale, c'est-à-dire en classant les interventions dans les bâtiments selon leur aspect final.

Mots clés: Ensanche de Barcelone; Quadrat d'Or; Ascenseurs et ajouts de bâtiments; Esthétique urbaine; Modification des façades.

Cómo citar. Zaar, M.H. y García Ávila, M.B. (2021): Ensanche de Barcelona. Una visión crítica de los remontes y añadidos en los edificios del "Quadrat D'Or". Anales de Geografía de la Universidad Complutense, 41(2), 505-531.

Sumario. 1. Introducción. 2. El "modelo Cerdà": historia, legislación y estudios realizados. 2.1. Precedentes del ensanche de Barcelona. 2.2. El Ensanche bajo las primeras leyes y ordenanzas municipales. 2.3. Ordenanzas Municipales de la Ciudad de Barcelona de 1891. 2.4. La consolidación del Ensanche en el inicio del siglo XX. 2.5. Las "Ordenanzas Congestivas" de 1942 a 1975. 3. Consecuencias para el Quadrat d'Or. 3.1. Morfología y estética: un análisis visual. 3.2. Análisis de las tipologías. 3.2.1. Armonizando con la obra original. 3.2.2. Contrastando mediante diseño y estructuras funcionales. 3.2.3. Semiocultos: Áticos y sobreáticos. 3.2.4. Simples. 3.2.5. Desacordes. 3.2.6. En voladizo. 3.2.7. Elementos superpuestos. 4. Conclusión. 5. Bibliografía.

\section{Introducción}

El Plan de Ildefonso Cerdà para el Ensanche de Barcelona se originó en el transcurso de la segunda mitad del siglo XIX, con el objetivo de presentar soluciones frente a la crisis urbana que afectaba tanto a Barcelona como a la mayor parte de las grandes ciudades europeas, como consecuencia de la alta densidad de población y la insalubridad.

Los estudios sobre este Plan, en los que se incorporan tanto el pensamiento de Cerdà, como la legislación que dio origen y continuidad al ensanche barcelonés, y las formas que éste fue adquiriendo a partir de la misma, se convirtieron en uno de los temas preferidos de urbanistas y geógrafos preocupados con la morfología urbana de dicho ensanche.

En ellos se puede contemplar, por un lado, la exaltación de sus ideas primigenias para una ciudad moderna, proporcionada e igualitaria, con viviendas en buenas condiciones de habitabilidad, áreas verdes proporcionales al área construida, amplias avenidas y calles con trazado regular; y por otro, duras críticas a la legislación que no solo permitió una paulatina ocupación de las manzanas, llegando a cerrarlas 
completamente, como vemos y padecemos en la actualidad, sino que además se reglamentó la edificación de una planta en su patio central, conocido como patio de manzana (Magrinyà, 2009).

Desde una mirada estética, uno de los aspectos que más llama la atención es la alteración de la morfología de las fachadas como consecuencia de la ampliación vertical de los edificios o de obra nueva añadida. Las ampliaciones de una o dos plantas, mas áticos y sobreáticos, son denominadas remontes.

Este artículo tiene como objetivo analizar las características de los remontes de las fachadas y los añadidos en los edificios situados en el Quadrat d'Or (Cuadrado de Oro) de Barcelona, zona central del Ensanche, caracterizada por una arquitectura rica al servicio de una nueva burguesía, para la que el estilo modernista, de un nutrido grupo de edificios, iba a ser su imagen, entendiendo que representaba el lujo y el refinamiento. La denominación Quadrat d'Or proviene de la exposición sobre Arquitectura Modernista acontecida durante la Olimpiada Cultural del año 1990, motivada por los Juegos Olímpicos de Barcelona92.

Comprende el Paseo de Gracia como eje vertebral y está delimitado por la Calle Aribau a la izquierda y el Paseo de Sant Joan a la derecha; las Rondas de Sant Pere y Universitat al sur y la Av. Diagonal al norte (Figura 1), donde se ubican, sobrios edificios de finales del siglo XIX que enlazan con otros muy característicos del Modernismo barcelonés, y obras realizadas durante todo el primer tercio del siglo XX, de marcado estilo Novecentista, el Noucentisme catalán, corriente clasicista de contestación al Modernismo.

Figura 1. Plano del Proyecto de Cerdà de 1859 y ubicación del Quadrat d'Or

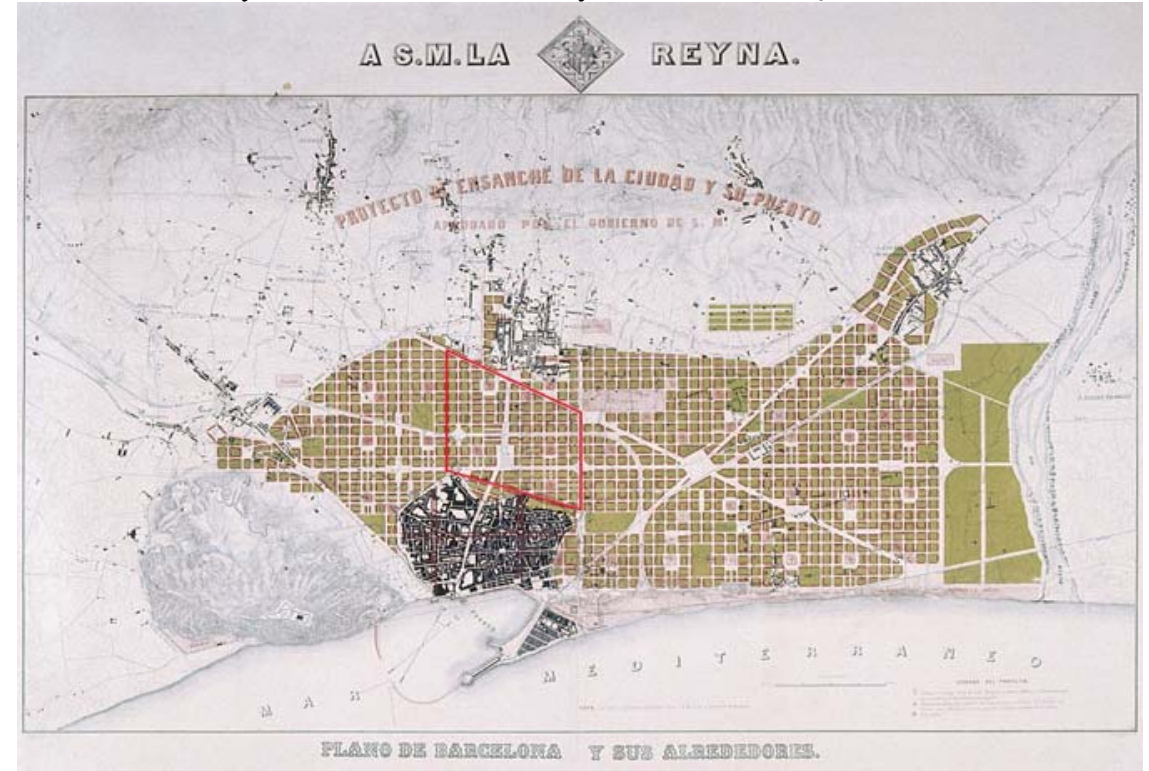

Fuente: Elaborado por los autores a partir del Museo Virtual de la Universidad de Barcelona. 
La razón de este análisis plástico se centra en el entendimiento de que, esta área del ensanche considerada "noble" porque en ella se localizan los edificios barceloneses más emblemáticos; constituye, a nivel urbanístico, estructural y de imagen, una entidad unitaria, por lo tanto, un todo indivisible urbanística, constructiva y morfológicamente que fue potenciado por las Ordenanzas Municipales de la Ciudad de Barcelona de 1891.

En el ámbito metodológico, consideramos fundamentales sus aspectos estéticos, la armonía propia del edificio y la relación de éste con las casas colindantes porque, aunque en algunos casos se ha obtenido un resultado simbiótico final digno, vemos que la mayoría de las veces los remontes y añadidos distorsionan gravemente la estética del ensanche.

Estructuramos el texto en dos apartados principales, además de esta introducción y de la conclusión. En el primer apartado elaboramos un breve recorrido sobre la historia y la legislación del Plan Cerdà; en él, abordamos el contexto en el que se originó el Ensanche de Barcelona, sus principales leyes y ordenanzas municipales, esenciales para elaborar el análisis de los remontes y añadidos. A continuación, elaboramos un análisis estético de los edificios que abarcan el denominado Quadrat d'Or, en el que estudiamos sus alteraciones morfológicas, en especial la concordancia o no entre los edificios originales y sus remontes, ya que estos añadidos fueron resultado de ordenanzas permisivas y de la especulación inmobiliaria.

\section{El "modelo Cerdà": historia, legislación y estudios realizados}

El Plan Cerdà comprendió varias fases, sometido siempre a las variaciones de las diferentes ordenanzas que fueron promulgándose, cuyas características influyeron en la estética de los edificios que analizamos. En este apartado, hacemos un breve examen de las mismas.

\subsection{Precedentes del ensanche de Barcelona}

En 1854 se autorizó el derribo de las murallas de Barcelona. En 1855 el Ministerio de Fomento encargó a Cerdá el levantamiento de un mapa topográfico del llano donde se proyectaría el Ensanche y él aprovechó este mapa para trabajar su proyecto, que en 1859 recibió el visto bueno del Gobierno Central. El Ayuntamiento de Barcelona haciendo caso omiso, convocó un concurso para hacer valer su oposición a este modelo. El concurso municipal lo ganó Antonio Rovira i Trias, que ideó una trama urbanística que responde a un modelo de ensanche contemporáneo y residencial semejante al Ring de Viena o al proyecto Haussmann de París, pero de nada le sirvió, porque la adjudicación a Cerdá era firme.

Los diez años que siguieron a la aprobación del Proyecto de Reforma y Ensanche de Barcelona de Ildefonso Cerdà se caracterizaron por una constante superación de obstáculos, resistencias, revisiones, problemas de fragmentación del proyecto debido a la persistencia de límites municipales y también de limitaciones económicas, 
resueltas con nuevos marcos normativos y el surgimiento de sociedades inmobiliarias con gran capacidad financiera (Guàrdia Bassols, 2009).

Los parámetros legales y administrativos que contribuyeron al Proyecto de Reforma y Ensanche de Barcelona fueron las Ordenanzas de Construcción (1859), el Pensamiento Económico (1860), el ensayo donde se creó la metodología de parcelación Cuatro palabras sobre el Ensanche (1861) y la Teoría General de la Urbanización (1867), todos de Ildefonso Cerdà.

Además, las sociedades inmobiliarias, como la Sociedad del Fomento del Ensanche dirigida por el propio Cerdà, asumieron muy pronto el papel protagonista en la discusión de las propuestas de ley para fomentar la edificación y la elaboración la primera Ley de Ensanche (1864) que se centró en tres aspectos fundamentales: el aprovechamiento edificatorio, la forma de costear y repercutir el suelo necesario para las calles, y la división de los terrenos en solares edificables (Joaquim Sabaté, 2009). Sin embargo, la fuerte especulación inmobiliaria que tuvo su punto crítico en 1866 con el crack financiero que afectó la Bolsa de Barcelona, llevó a que, en su mayoría, dejasen de actuar como agentes de construcción.

Fue por esta razón que, en la construcción del Ensanche de Barcelona durante la segunda mitad del siglo XIX, hubo una reducida presencia de sociedades inmobiliarias. Crecieron en importancia los grupos de grandes promotores y los profesionales de la construcción que formaban parte de ellos. Estos llegaron a construir el $57 \%$ de los edificios, aportando el 50\% de los capitales invertidos y una cifra semejante de la superficie construida (Tafunell, 1994; Tatjer, 1996).

Uno de los puntos que queremos destacar de la Ley de Ensanche de 1864 es que recogió la nueva forma urbanística y estableció que su gestión se daría a través de las Juntas de Ensanches. Una vez consolidadas éstas, establecerían el precio de las expropiaciones y gestionarían las contribuciones territoriales al margen del presupuesto municipal.

Con una segunda Ley de Ensanche aprobada en 1876, estas Juntas se denominaron Comisiones de Ensanche y, según Francesc Magrinyà, "se convirtieron [..] en los verdaderos urbanizadores de la ciudad hasta 1953, año en el que se aprobó el Plan Comarcal de Barcelona". Aunque en un marco legal precario en instrumentos, "Cerdà había conseguido articular unos mecanismos de reparcelación efectivos para la construcción inicial del Ensanche y la introducción de las Comisiones de Ensanche que se convertirían en el agente urbano clave para la construcción del mismo" (Magrinyà, 2009).

En las ideas desarrolladas en la Teoría General de la Urbanización (1867), Cerdà planteaba aplicar principios que darían preferencia a las viviendas y a las manzanas frente a la ciudad; proporcionando también, un espacio distinto asociado a cada uso y medio de locomoción: peatón, carruajes y ferrocarril.

La manzana, con edificación perimetral mediante viviendas entre medianeras, un gran patio central ajardinado y chaflanes en sus esquinas, insertados en una parcelación regular con anchuras de calles que diferirían, de acuerdo con la importancia que les atribuyese el Ensanche, sería la unidad básica. Las Ordenanzas de Parcelas (1860-90) eran el mecanismo que regulaba tanto su superficie edificable, 
que en este período solo permitía el cincuenta por ciento de la parcela, cómo la altura reguladora máxima que pasó de 16 metros iniciales a 20 metros.

Como consecuencia, la construcción de casas entre medianeras fue la alternativa más generalizada. Inicialmente con planta baja y tres pisos y perceptiblemente más profundas que las casas del chaflán, albergaban en su planta principal (primera planta) la vivienda del propietario valorada "tanto por la posibilidad de ser visto como por la de ver" (Tatjer, 2009).

\subsection{EI Ensanche bajo las primeras leyes y ordenanzas municipales}

Aunque la discusión sobre el ensanche de ciudades en España comenzó a finales la primera mitad del siglo XIX, el inicio de la primera etapa del Ensanche de Barcelona coincidió con el Bienio Progresista de 1854-56 y tanto en éste como en el Ensanche de Madrid, tuvo un papel esencial el Proyecto de Reforma y Ensanche de Barcelona de 1859 de Ildefonso Cerdà.

En la década de 1860, aconteció la primera ola de urbanización y construcción del Ensanche. Se caracterizó por casas burguesas aisladas con jardines, localizadas en el paseo de Gràcia, principal arteria de esta nueva trama urbana que sería edificada en detrimento del centro tradicional y de las Ramblas. Se ocupó el sector central ya consolidado como el mejor y que se situaba entre rambla de Catalunya y calle Pau Claris, y entre Consell de Cent y Ausiàs Marc, actual Eixample derecho (García Espuche, 2002). Hecho que está en consonancia con el principio de conducta de la burguesía urbana catalana de canalizar una proporción elevada y estable del ahorro hacia la inversión en vivienda (Tafunell, 1989).

A partir de 1867, orientado por el Reglamento del mismo año y más tarde por la Ley del Ensanche de 1876, las experiencias tomaron una dimensión mucho menor, sobre todo a partir de la Restauración (1875) porque se vivió un período conservador y marcado por el poder de los propietarios. En esta etapa se dio mayor importancia a los proyectos arquitectónicos pactados directamente con los propietarios, y fue cuando la composición adquirió un mayor protagonismo, y se fue olvidando la reforma propuesta por Cerdá, hasta el punto de que la tendencia era considerar solamente el Ensanche (Aibar Puentes, 1995).

La Exposición Universal de 1888 tuvo un papel importante en la formación del Ensanche con la devolución a la ciudad del recinto militar de la Ciudadela, que finalizó en 1885. Estos hechos, acompañados del auge económico, condujo a la construcción masiva y fue decisivo para la modernización de la ciudad: se concluyó la parte más valiosa del Ensanche, entre el paseo de Gràcia y el paseo de Sant Joan, se consolidó el área entre los edificios de la Universitat de Barcelona y del Mercat de Sant Antoni y se promovió el barrio del Poble Sec (Guàrdia Bassols, 2009).

\subsection{Ordenanzas Municipales de la Ciudad de Barcelona de 1891}

En los inicios de 1890 la jerarquización del Ensanche ya estaba definida. El espacio considerado "central" y donde vivía la burguesía más adinerada se vigorizó, 
esencialmente entre la plaza de Catalunya, paseo de Gràcia y rambla de Catalunya, aunque se prolongase hasta el Paseo de Sant Joan perdiendo fuerza a medida que se aproximaba al mismo. Hacia a la izquierda, sin embargo, el avance era tímido y se expandía, aunque parcialmente, hasta calle Balmes y Aribau. Además, la Gran Vía fue, durante este mismo período, el eje paralelo al mar más importante del ensanche.

En este contexto, las Ordenanzas Municipales de la Ciudad de Barcelona de 1891, en su título Cuarto, introdujeron importantes cambios en la legislación vigente hasta entonces, que hacían referencia a la superficie edificable en las manzanas.

En cuanto a las características de las casas y su plasticidad, los arquitectos Rogent y Pedrosa han señalado que esta Ordenanza de 1891 permitió un mayor volumen en el tratamiento de las fachadas ya que pasó a controlar solo un reducido número de parámetros como la proporción entre la altura reguladora máxima y la anchura de la calle. Esta posibilidad de desarrollar las fachadas sin más límite que la alineación de la calle, hizo factible el desarrollo del Modernismo, estilo paradigmático asumido por una creciente burguesía local "ansiosa de grandeza".

Para las fachadas y sus vuelos o salientes estas Ordenanzas establecían que:

Art. 124. Todo propietario es árbitro de adoptar para la fachada de su edificio el tipo de arquitectura que más le plazca, mientras el proyecto no constituya un conjunto extravagante o ridículo. (...)

Artículo 125. Sin perjuicio de lo dispuesto en el art. 117, los propietarios podrán terminar las fachadas de sus casas, bien en una línea horizontal a su altura, bien colocando sobre las mismas frontones rectos o curvos, escudo de armas, atributos y estatuas, a condición de que sean solo elementos decorativos del conjunto de las fachadas y no sirvan de pretexto para cometer abusos que estén en discordancia con las reglas precedentes.

Artículo 126. En la construcción de mesetas de balcones, miradores o tribunas, marquesinas, montantes, cornisas, arcos, aleros, saledizos o cualquier otro cuerpo saliente sobre la alineación de fachada, el máximum de salida no podrá exceder de la 1/5 parte de la distancia que separe dicha alineación del eje de la calle o plaza paralelo al frente del edificio.

Jamás será, empero, el vuelo mayor de 1,50 m., cuando tenga forma recta, ni de 2m., cuando sea poligonal o circular.

Artículo 129. Se prohíben los arcos y puentes de una parte a otra de calle (Ordenanzas Municipales de la Ciudad de Barcelona, 1891).

Sobre las líneas de fachada hacia dentro, en los terrados de los edificios, el artículo 118 de estas mismas Ordenanzas establecía:

En la mitad del fondo edificado, paralelamente al muro de fachada y a una altura que no podrá exceder de 3 metros sobre la elevación máxima consentida, se supondrá una línea horizontal. Debajo del plano inclinado de unión de dicha horizontal con la línea de cornisa de las fachadas principal y posterior, podrán 
construirse cajas de escalera, torres, palomares, departamentos de servicios o la cubierta definitiva de la totalidad del edificio.

Se exceptuarán, no obstante, de esta regla las cajas de escalera inmediatas a la primera crujía, a las cuales podrá darse la altura de 3 metros, aunque sobresalgan en parte de dicho plano inclinado.

También quedan exceptuados los tubos de chimenea y ventilación, las paredes divisorias de los predios, que podrán tener un metro de altura en toda su longitud, los antepechos calados de las torres y los armazones de madera de los palomares (Ordenanzas Municipales de la Ciudad de Barcelona, 1891).

Además, dichas Ordenanzas señalaban que las casas podrían tener el número de pisos que sus propietarios quisieran, siempre que la altura de estos no fuera menor de 2,80 metros de luz en las casas cuya altura fuera de 20 metros, y de 3 metros de luz en las demás. Sin embargo, toleraban la construcción de entresuelos interiores o altillos en las tiendas cuya altura fuera de 5 metros, siempre que tuviesen sus habitaciones traseras abertura directa a un patio o jardín (Ordenanzas Municipales de la Ciudad de Barcelona, 1891).

Felizmente no se permitió alterar la altura de los edificios, estos solo podrían llegar a los 22 metros si la anchura de la calle excediera de 20 metros. Tampoco se podía "subir pared alguna del edificio, ni otro objeto colocado sobre el mismo en la fachada", solo la "colocación de un antepecho calado de hierro u otro material, de 1 metro de elevación" (Ordenanzas Municipales de la Ciudad de Barcelona, 1891), lo que contribuyó al mantenimiento de la estética de la fachada exterior de las manzanas del ensanche.

\subsection{La consolidación del Ensanche en el inicio del siglo XX}

En las primeras dos décadas del siglo XX, también como consecuencia de las Ordenanzas de 1891, se produjo una importante expansión del Modernismo arquitectónico en Barcelona, también conocido como Art Noveau. Fue un fenómeno europeo, que comenzó hacia 1890 teorizado e impulsado por William Morris, convirtiéndose en uno de los últimos movimientos románticos del arte, que tuvo su apogeo en el cambio de siglo y concluyó unos años más tarde (García Ávila, 2005).

Con el Modernismo, el área central del ensanche se densificó. La zona próxima a la plaza de Catalunya, urbanizada y ajardinada en 1902 y el paseo de Gràcia se convirtieron, a partir de los primeros quince años del siglo XX en el espacio residencial y comercial preferido de la burguesía catalana, tanto con la construcción de nuevos edificios, como con la reforma y embellecimiento integral, o solo de las fachadas. El ensanche central se caracterizó por una gran densidad constructiva en función de la nueva demanda de los diversos sectores económicos. Edificios de poca altura construidos en las décadas de los sesenta, setenta y ochenta del siglo XIX fueron derribados y sustituidos por otros que aprovecharon más el espacio, conforme explica Albert García Espuche, 
El aumento del valor del suelo ha hecho rentable el derribo para edificar: es interesante recordar, en este sentido, que en el emplazamiento de La Pedrera (Casa Milá) había antes un palacete urbano, un edificio que, como en muchos otros casos, fue sustituido por otro de volumen edificado muy superior.

El desplazamiento constante de diferentes sectores de la burguesía, la distribución espacial de los comercios, de la industria, o del servicio doméstico y la adquisición de nuevos equipamientos técnicos como ascensores, ayudan a subrayar la idea de un Ensanche central como área burguesa por excelencia (García Espuche, 2002).

El ritmo de esta ocupación refleja sus resultados. Según Cèlia Cañellas y Rosa Toran

La orientación preferente de la construcción hacia el Ensanche y los núcleos antiguos del Plan (Cerdá) fue ostensiblemente ascendente y derivó de 142 edificaciones de nueva planta en 1904 a 316, diez años después. Este ritmo constructivo fue acompañado de la ampliación de plantas en casas ya levantadas, proceso que culminó el año 1911 con adiciones de pisos en el ensanche (Cañellas y Toran, 1990).

En este período comenzó a ser edificada la avenida Diagonal. Su primer trazado se realizó en 1884 entre calle Pau Claris y paseo de Gràcia en 1896 en el "entonces llamado Camp d'En Tuset, pero también un poco hacia la dirección contraria: hasta la calle Bruc" (Permanyer, 2001). Al mismo tiempo, el tramo que comprende el paseo de Gràcia y las proximidades de calle Aribau se transformó en un espacio privilegiado de la burguesía catalana, con palacetes ajardinados, edificios importantes y pisos de alta calidad, con mayor valoración a medida que se acercan al paseo de Gràcia.

La obra más vistosa de la Avenida Diagonal es la Casa de les Punxes (en el n ${ }^{\circ}$ 420), construida entre 1903 y 1905 por el arquitecto Puig i Cadafalch, autor también del palacete del Barón de Quadras (avenida Diagonal, 373) edificado entre 1902 y 1904, y de la Casa Serra (esquina con rambla de Catalunya) de 1905. Destacan, asimismo, la Casa Comalat (avenida Diagonal, 442) de 1911 del arquitecto Salvador Valeri i Pupurull, el Palau Pérez Samanillo de 1910 (avenida Diagonal, chaflán con calle Balmes) del arquitecto Joan Josep Hervàs, y la Casa Sayrach (avenida Diagonal, 423) construida en 1918 por Manuel Sayrach.

Mientras algunos sectores burgueses y aristócratas prefirieron edificar sus palacetes en el área de confluencia entre paseo de Gràcia y avenida Diagonal, otros optaron por construir sus casas de verano en los núcleos urbanos de Sarrià, Les Corts o Sant Gervasi, donde disfrutaban de amplias áreas verdes.

\subsection{Las "Ordenanzas Congestivas" de 1942 a 1975}

A mediados del siglo XX, la aplicación de nuevas ordenanzas, asociadas a una intensa especulación inmobiliaria, incrementaron la densidad del ensanche, produciendo 
importantes cambios en su estética. El área denominada Quadrat d'Or, objeto de este estudio, no estuvo al margen de esta legislación ni de sus consecuencias.

Las "Ordenanzas Congestivas", como las denomina Joan Busquets, estuvieron en vigor entre 1942 y 1975 . Alteraron la altura reguladora máxima hasta los 24,4 metros, permitiendo construir incluso 7 plantas más ático y sobre ático y edificar el patio de manzana a una altura de 5,5 metros y fueron las responsables de la densificación y el deterioro estético del ensanche de Barcelona.

Busquets se refiere así a ellas: "Esta ordenanza rompe el skyline del Eixample y además fomenta los funestos levantamientos sobre edificios anteriores para alcanzar la nueva altura permitida, que tanto ha contribuido a fragmentar la imagen urbana del conjunto. Evidentemente las densidades resultantes aumentan de una forma dramática" (Busquets, 2004).

Así mismo, Mercedes Tatjer señala que la permisividad y la falta de respeto a la estética del edificio preexistente dieron origen a grandes transformaciones en el paisaje del Ensanche de Barcelona:

La permisividad, la tolerancia, cuando no la corrupción con que se aplicaban las normas -las viviendas ilegales en las terrazas, las grandes terrazas y tribunas que sobresalían hacia la calle, la continuada ocupación de los interiores de las manzanas con edificaciones de incluso dos plantas, las diferentes plantas de aparcamientos subterráneos- en una ciudad sin democracia municipal, acabarían convirtiendo el Eixample en uno de los símbolos de la especulación urbanística de la etapa Porcioles.

Los nuevos pisos levantados sobre edificios ya construidos, realizados en muchos casos con materiales pobres y sin respetar la construcción de la casa existente, pusieron "sombrero" a muchos de ellos (Tatjer, 2009).

Esto se puede observar en las Ordenanzas Municipales de la Ciudad de Barcelona de 1947, en la Sección $3^{\text {a }}$, Subsección 1 que trata de las alturas y otras dimensiones:

Art. 372: Los edificios de la Zona General podrán tener, en relación de la anchura de las calles en que están emplazados, las alturas reguladoras máximas que se expresan en el siguiente cuadro, en el que se indica el número tope de plantas que pueden comprenderse dentro de dichas alturas:

(...) De 20 a menos de 30 metros: 24,40 metros: planta baja y 6 pisos.

Además, las Ordenanzas Municipales de Edificación de 1958 en su Título Primero (Ordenanzas de Volumen), Capítulo $3^{\circ}$, mantuvo en las calles del Ensanche, la altura reguladora máxima de 24,40 metros, con planta baja más 6 pisos (Ordenanzas Municipales de Edificación, 1958).

Las mismas Ordenanzas Municipales de Edificación, en su Título Cuarto que trata de las Ordenanzas de Estética, establecen en su artículo 140 que: 
I. A los efectos de lo dispuesto en los artículos siguientes se conceptuarán como fachadas todos los paramentos de un edificio visible desde la vía pública. En particular, cuando se trate de edificios contiguos cuya diferencia de alturas máximas permitidas sea igual o superior a la de una planta, será obligatorio tratar como fachada el paramento que por tal causa queda visto, el cual deberá retirarse de la línea medianera para poder establecer en él aberturas, si ello fuera necesario para conseguir una composición adecuada, a menos que se establezca en debida forma la correspondiente servidumbre.

II. Se declaran libre de composición las fachadas de los edificios, excepto cuando se proyecte emplazarlos en calles, manzanas o sectores de la Ciudad para los que rija un modelo especial obligatorio, o en lugares donde deba, o simplemente convenga, conservar o establecer un carácter arquitectónico o urbanístico acusado, pudiendo exigirse en todos estos casos el empleo de materiales y sistemas constructivos determinados. No obstante, se evitarán siempre efectos discordantes entre las fachadas de una misma manzana, contiguas o próximas, al objeto de obtener un buen efecto urbanístico de conjunto.

III. Podrá, además, denegarse da licencia de edificación a los proyectos que constituyan un ataque al buen gusto o resulten extravagantes, ridículos o impropios de su emplazamiento (Ordenanzas Municipales de Edificación, 1958).

Tardía, pero acertadamente, las Ordenanzas del Plan General Metropolitano de 1976 contemplan la reducción de la altura reguladora máxima de los edificios que, en función del ancho del vial, (de 20 a menos de 30 metros), se redujo de los 24,40 a los 20,75 metros y cinco plantas (Normativa Urbanística Metropolitana, 2004).

En la Normativa de Texto Refundido de la Ordenanza de Rehabilitación y Mejora del Ensanche, artículo 23, sobre Coronamientos, constan normas estéticas puntuales sobre los remates finales de los remontes:

La cornisa o elementos de coronamiento del edificio preexistente, cuando sea original o posea un valor arquitectónico o artístico intrínseco, será desplazado y adoptado para rematar la fachada remontada excepto cuando, por constituir una parte esencial en la composición del edificio, habrá de conservarse como un apoyo de la nueva intervención (Butlletí Oficial de la Provincia de Barcelona, $\mathrm{n}^{\circ}$ 297, 2002).

En esta coyuntura y con el objetivo de atenuar el proceso de gentrificación asociado a la especulación inmobiliaria y al turismo de masas que, en Barcelona y otras ciudades mediterráneas se incrementó durante la segunda mitad de siglo XX (Zaar, 2017 y 2019), se echan en falta ordenanzas municipales específicas y completas para el control de los remontes y añadidos en edificios preexistentes. 


\section{Consecuencias para el Quadrat d'Or}

Como hemos visto, la actual configuración del ensanche barcelonés es resultado básicamente de cuatro etapas normativas. Una primera, en vigor entre 1860 y 1890 , que trataba de la ordenanza de las parcelas, mediante la que se permitía edificar el $50 \%$ de estas y una altura reguladora máxima igual al ancho habitual de las calles, o sea 20 metros.

Le siguieron entre 1891-1941 las Ordenanzas Municipales de la Ciudad de Barcelona que posibilitó un mayor volumen en el tratamiento de las edificaciones y solo controló aspectos como la proporción entre la altura reguladora máxima y el ancho de la calle. Su artículo 184, referente a obras de carácter artístico o monumental, facilitó a Antonio Gaudí, la construcción de La Pedrera, "la casa extraña" de sensuales ondulaciones que, por encima de su afiliación estilística, es funcional, es arquitectura, permitiéndole cierta conculcación de las normativas de edificación, como es el caso del pilar "pata de elefante" que, por invadir la acera del paseo de Gràcia, el consistorio pretendió amputar (Entrevista de Asha Miró a Lluís Permanyer, 2017).

Posteriormente, fue a través de las "Ordenanzas Congestivas" (1942 a 1975), cuando se produjeron las alteraciones estéticas de mayor peso en el ensanche, y una excesiva densificación de las manzanas. La altura reguladora máxima se situó en los 24,4 metros, permitiendo planta baja más siete y ático y sobreático, alterando el skiline del ensanche y dio pie a los añadidos y remontes realizados sobre edificios preexistentes hasta alcanzar la altura permitida. Una normativa que como hemos visto fue sustituida en 1976, por las Ordenanzas del Plan General Metropolitano que limitó la altura reguladora máxima a 20,75 metros.

\subsection{Morfología y estética: un análisis visual}

Lejos de ser una nimiedad sin mayores consecuencias, en un alto porcentaje los remontes y añadidos -conocidos por los barceloneses como barrets (sombreros)fueron construidos de una forma tan incoherente, como lo era la normativa municipal de edificación que los permitió, ya que tanto las ordenanzas sobre composición de fachadas como la altura reguladora máxima variaron igual hacia la permisividad, como hacia la restricción, en diferentes épocas, dependiendo de la orientación estética -cuando la había- de las autoridades municipales (Capel, 2005). Se trata en estos casos, de una perturbación formal que merece una exposición crítica, considerando su status quo desalentador.

Para proceder a la evaluación sobre la preservación o no de las características de las fachadas originales de cada edificio con la construcción de remontes, hemos tenido en cuenta la estética original del edificio y hemos observado y valorado hasta qué punto su aspecto actual es resultado de una intervención cuidada o no, valorando si se buscó esa "plasticidad" que menciona la Ordenanza de Manzana de 1891.

El trabajo de campo nos posibilitó realizar, a partir del nivel de las calles, un análisis visual de los edificios y de sus características. El objetivo fue elaborar este 
estudio a partir de la perspectiva de un peatón que se posiciona frente al edificio, observando la casa en "contrapicado" desde la acera propia y desde la perspectiva que da la acera de enfrente. El procedimiento habitual fue reflejarlo en un cuadro, constatando calle y número de los edificios afectados por ampliaciones y añadidos, anotando en las casillas correspondientes las variaciones morfológicas que fuimos apreciando.

Cuadro 1. Paseo de Gracia. Características de los remontes y añadidos.

\begin{tabular}{|c|c|c|c|c|c|c|c|}
\hline Localización & $\begin{array}{c}\text { Armonizando } \\
\text { con la obra } \\
\text { original }\end{array}$ & $\begin{array}{c}\text { Contrastando } \\
\text { mediante } \\
\text { diseño y } \\
\text { estructuras } \\
\text { funcionales }\end{array}$ & $\begin{array}{c}\text { Semiocultos: } \\
\text { Áticos y } \\
\text { sobreáticos }\end{array}$ & Simples & Desacordes & $\begin{array}{c}\text { En } \\
\text { Voladizo }\end{array}$ & $\begin{array}{c}\text { Elementos } \\
\text { Superpuestos }\end{array}$ \\
\hline paseo de Gràcia, 3 & & $\mathrm{X}$ & $\mathrm{X}$ & & & & \\
\hline paseo de Gràcia, 5 & $\mathrm{X}$ & & $\mathrm{X}$ & & & & \\
\hline paseo de Gràcia, 15 & $\mathrm{X}$ & & $\mathrm{X}$ & & & & \\
\hline paseo de Gràcia, 20 & & & $\mathrm{X}$ & & $\mathrm{X}$ & & \\
\hline paseo de Gràcia, 25 & $\mathrm{X}$ & & $\mathrm{X}$ & & & & \\
\hline paseo de Gràcia, 28 & $\mathrm{X}$ & & & & & & \\
\hline paseo de Gràcia, 29 & $\mathrm{X}$ & & $\mathrm{X}$ & & & & \\
\hline paseo de Gràcia, 34 & & $\mathrm{X}$ & & & & & \\
\hline paseo de Gràcia, 37 & & & Solo Ático & $\mathrm{X}$ & & $\mathrm{X}$ & \\
\hline paseo de Gràcia, 42 & $\mathrm{X}$ & & $\mathrm{X}$ & & & & \\
\hline paseo de Gràcia, 45 & $\mathrm{X}$ & & $\mathrm{X}$ & & & & \\
\hline paseo de Gràcia, 47 & & & & & $\mathrm{X}$ & & \\
\hline paseo de Gràcia, 52 & & & $\mathrm{X}$ & $\mathrm{X}$ & $\mathrm{X}$ & & \\
\hline paseo de Gràcia, 62 & & & $\mathrm{X}$ & & $\mathrm{X}$ & & \\
\hline paseo de Gràcia, 68 & & & & & & & $\mathrm{X}$ \\
\hline paseo de Gràcia, 69 & $\mathrm{X}$ & & $\mathrm{X}$ & & & & \\
\hline paseo de Gràcia, 71 & & & & $\mathrm{X}$ & & $\mathrm{X}$ & $\mathrm{X}$ \\
\hline paseo de Gràcia, 73 & & $\mathrm{X}$ & & & & & \\
\hline paseo de Gràcia, 75 & & $\mathrm{X}$ & $\mathrm{X}$ & & & & \\
\hline paseo de Gràcia, 81 & $\mathrm{X}$ & & & & & & \\
\hline paseo de Gràcia, 86 & & & $\mathrm{X}$ & $\mathrm{X}$ & & $\mathrm{X}$ & \\
\hline paseo de Gràcia, 90 & $\mathrm{X}$ & & $\mathrm{X}$ & & & & \\
\hline paseo de Gràcia, 95 & & & & & $\mathrm{X}$ & & \\
\hline paseo de Gràcia, 97 & & & $\mathrm{X}$ & & $\mathrm{X}$ & & \\
\hline paseo de Gràcia, 101 & $\mathrm{X}$ & & $\mathrm{X}$ & & & & \\
\hline paseo de Gràcia, 102 & & & $\mathrm{X}$ & & $\mathrm{X}$ & & \\
\hline paseo de Gràcia, 110 & $\mathrm{X}$ & & $\mathrm{X}$ & & & & \\
\hline
\end{tabular}

Fuente: Trabajo de campo de los autores 
El desarrollo de este estudio, hemos analizado los remontes de 298 casas y clasificado sus fachadas, según patrones estéticos fundamentales, como la armonía del añadido respecto al edificio preexistente, el resultado de la aplicación de diseños contrastando con la obra original, los añadidos semiocultos, los remontes en voladizo, los impropios o antiestéticos o los elementos superpuestos, que perturban gravemente la armonía del conjunto urbanístico del Quadrat d'Or. Las calles más emblemáticas son las que más los han sufrido, sirva de ejemplo que la rambla de Catalunya es, con diferencia la vía más afectada por estos, con 38 intervenciones, lo que representa un $12 \%$ del total.

Para ejemplificar la metodología empleada, incluimos a continuación, el resultado correspondiente al paseo de Gràcia, que, por ser la vía principal, fue una de las áreas más codiciadas por la vorágine especulativa. En ella constatamos remontes de 19 áticos y sobreáticos, 4 remontes muy simples y 7 desacordes con la casa original. También consideramos muy probable que por ser un paseo tan emblemático y de gran envergadura económica, casi se libró de las ampliaciones más extravagantes, puesto que, de las 26 casas analizadas, solo vimos 3 remontes en voladizo, un añadido en terraza y un observatorio astronómico abandonado, así como 4 remontes muy simples, algo insólito por tratarse de una zona adinerada (cuadro 1).

\subsection{Análisis de las tipologías}

Para este estudio hemos agrupado los remontes y añadidos en siete tipologías, ateniéndonos al resultado estético y a su presencia integral y global, esto es, clasificando las intervenciones en las fachadas de los edificios por su aspecto final, observando desde las más miméticas y las que aportan un fuerte contraste, hasta las más impropias y antiestéticas, a saber: 1. Armonizando con la obra original, 2. Contrastando mediante diseño y estructuras funcionales, 3. Semiocultos: Áticos y Sobreáticos, 4. Simples, 5. Desacordes, 6. En voladizo, y 7. Elementos superpuestos.

\subsubsection{Armonizando con la obra original}

En varios de los edificios analizados se observa una armonización con la obra original. Esto es así básicamente, porque los añadidos fueron realizados siguiendo la pauta estilística de la construcción original y se actuó en consecuencia, prolongando verticalmente los paramentos, continuando la estética de las molduras, los dinteles y otros elementos ornamentales, si los hubiera en la casa existente. Como ejemplos hemos tomado los remontes de dos inmuebles, el de paseo de Gràcia, 101, que aumenta dos plantas visualmente muy bien encajadas en esta definición de unidad con la construcción primitiva, buscando un resultado sobrio, acorde, donde solo se altera la armonía por el remonte de ático y sobreático (figura 2), y el de dos plantas, también, -aunque en la figura solo se aprecia una- construido ampliando la casa $\mathrm{n}^{\circ} 28$, del paseo de Gracia, retrasando algo la fachada, en perfecta armonía con la ecléctica y armoniosa obra primigenia (figura 3 ). 
Figuras 2 y 3 . Armonizando con la obra original
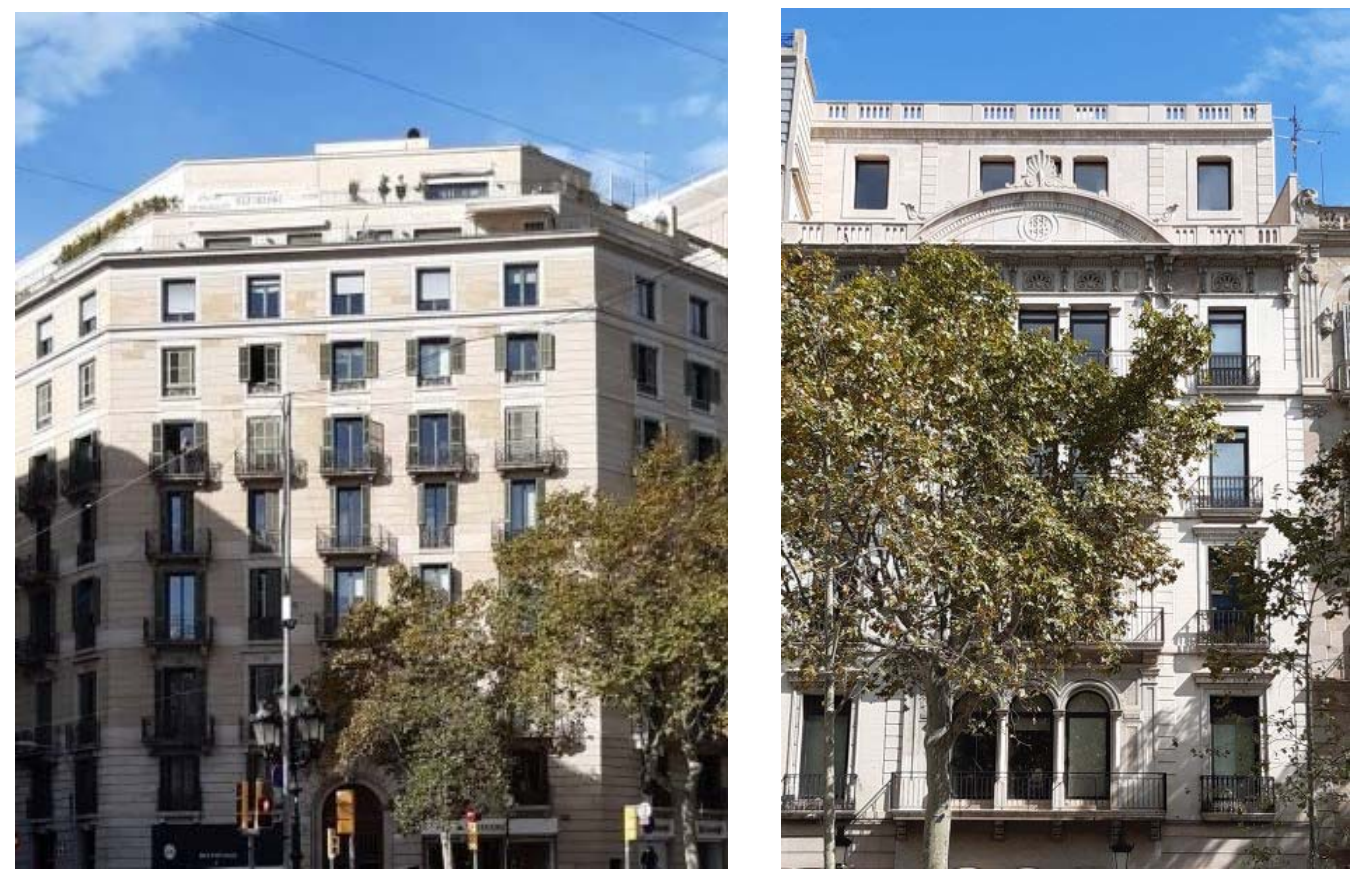

$\left({ }^{*}\right)$ Nota. Localización de los edificios. Figura 2: paseo de Gràcia, 101. Figura 3: paseo de Gracia, 28.

Fuente: Foto de los autores.

Con esta tipología, que se caracteriza por la consonancia, solo hemos encontrado 12 inmuebles remontados, un $4 \%$ del total de edificios estudiados.

\subsubsection{Contrastando mediante diseño y estructuras funcionales}

Los remontes o añadidos, también significaron un cambio radical en la morfología de los edificios intervenidos, cuando se realizaron contrastando mediante diseño funcional y con nuevos materiales. El resultado suele ser impactante, la innovación técnica y tipológica en casos concretos demuestra que puede darse una simbiosis atractiva.

Un ejemplo importante es el remonte realizado en 1992, por los arquitectos Bohigas, Martorell y Mackay, en el Palacio de Vedruna, neoclásico tardío, construido en 1883 en calle Pau Claris, 150 y que forma parte del Patrimonio Arquitectónico de Cataluña, para transformarlo en un emblemático hotel de lujo (figura 4). Se realizó yuxtaponiendo la ampliación sobre la obra original con un espacio hundido, como una 
franja de separación, lo que le ayuda a incorporar la funcionalidad de la ampliación y le confiere un aspecto formal sobrio.

Figuras 4, 5, 6 y 7. Contrastando mediante diseño y estructuras funcionales
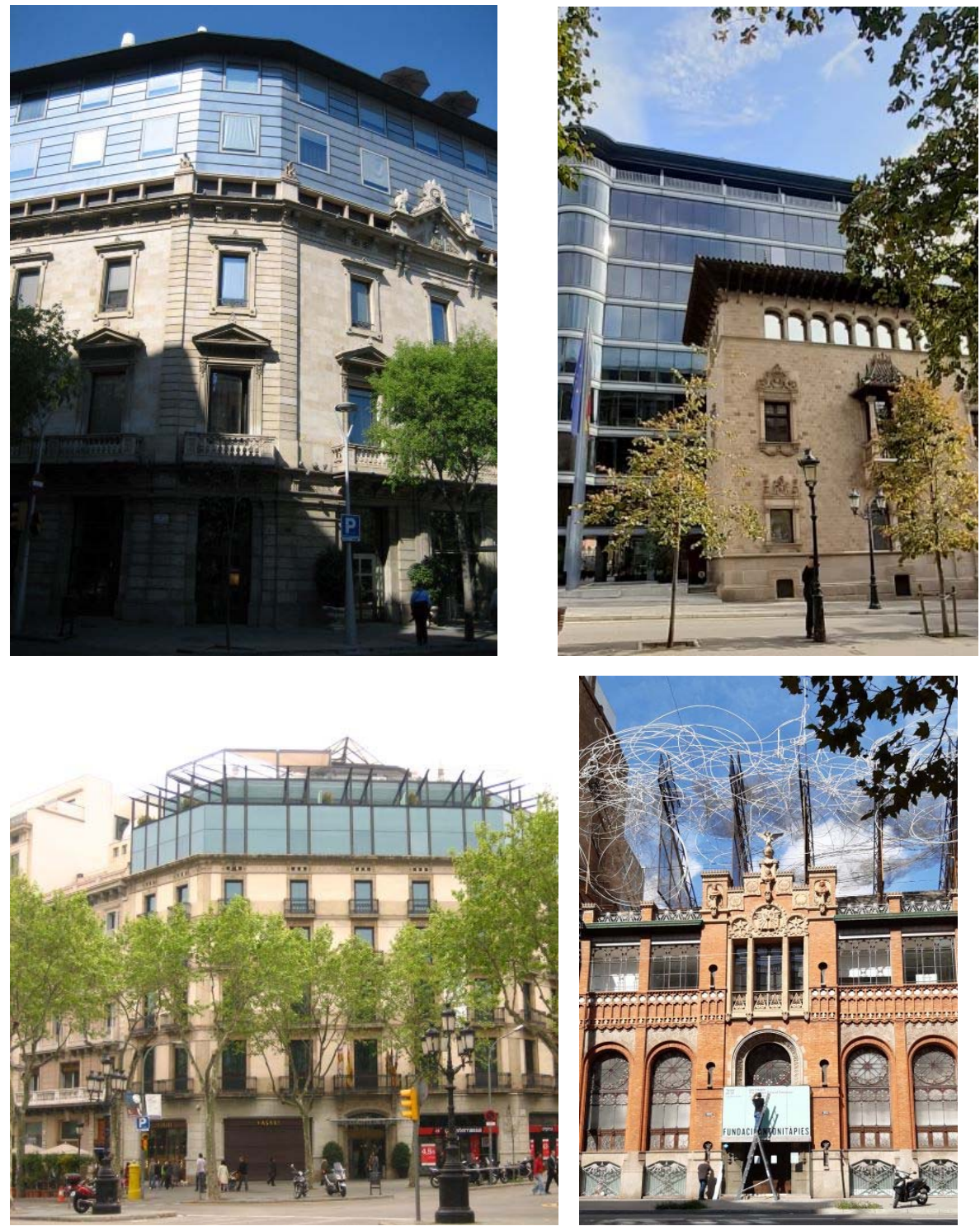

(*) Nota. Localización de los edificios. Figura 4: calle Pau Claris, 150. Figura 5: Casa Serra, rambla de Catalunya, 126. Figura 6: paseo de Gràcia, 73. Figura 7: Fundació Tapies, calle Aragó, 225.

Fuente: Foto de los autores 
Otro muy destacable es el "añadido" a la Casa Serra, en rambla de Catalunya, 126, construida en 1903 por el arquitecto modernista-historicista Puig i Cadafalch, de factura gótico-nórdica, y con ornamentación plateresca, que fue declarada Bien Cultural de Interés Nacional por la Generalitat. En 1984 la adquirió la Diputación de Barcelona, para instalar su nueva sede. Para dar capacidad a las nuevas instalaciones, los arquitectos Federico Correa y Alfonso Milá le adosaron en el espacio posterior un imponente edificio funcional, contrastando y empoderándose de la perspectiva, aunque respetando plenamente esta antigua y ecléctica obra, tan ligada a la cultura catalana. Este respeto en el trato de la casa de Puig i Cadafalch no evitó la polémica que se desató durante más de 20 años (Rebés Solé, 02/05/2005) (figura 5).

En paseo de Gracia 73, edificio destinado a hotel, observamos otro remonte de hierro y cristal, muy peculiar, por ser continuación del inmueble medianero de nueva planta, en calle Mallorca, 250. Realizado en 2014, por el estudio de arquitectura Factoría UDA, consistió en aumentar una planta y un ático con una estructura muy exteriorizada, posee una gran terraza y piscina (figura 6). Viene a colación comentar que, desde esta terraza descubrimos que enfrente, en el terrado de la Casa Enric Batlló (paseo de Gracia, 75), edificada en 1896, por el premodernista Josep Vilaseca i Casanovas, el arquitecto Oscar Tusquets, quien reivindica "la relación mágica entre el cerebro y la mano" (Luque, 2020), proyectó el año 2016, una reforma integral para convertirla en hotel. Para esto, levantó un ático, retrasándolo correctamente de la alineación de la fachada, lo que le hace imperceptible desde la calle, tanto que, en un principio nos pasó desapercibido en nuestro trabajo de campo.

Queremos citar también en este apartado el añadido de Antonio Tapies sobre el terrado de su propia fundación, situada en calle Aragó, 225. Se trata de un edificio construido entre 1881 y 1885 por Lluís Doménech i Montaner, de tipología industrial, ecléctico y que en absoluto detenta características modernistas, dada su simetría morfológica y la sencillez constructiva de su fachada, que combina la utilización de ladrillos y hierro. Desde la acera opuesta, frente al edificio, sorprende un añadido plástico o estético, que consiste en una especie de escultura espacial, etérea, de gran volumen, 12,7 metros de altura, 24 metros de longitud y 6,8 metros de profundidad, realizada con alambres enredados en un laberinto, denominada Núvol i Cadira (Nube y Silla), que ocupa todo el frontal del terrado y está sujeta por ocho estructuras de hierro perpendiculares a la fachada, que respetan la alineación de la calle (figura 7). Es comprensible que este añadido, tampoco haya podido evitar la polémica.

De los 298 edificios estudiados hemos encontrados 25 remontes realizados con estructuras contrastantes, lo que equivale a un $8,3 \%$ del total.

\subsubsection{Semiocultos: Áticos y sobreáticos}

Teóricamente, los remontes de esta tipología no deben aparecer a la vista, si se han respetado las normas de edificación, retrasando la fachada del ático tres metros y otros tres la del sobreático, formando un ángulo de cuarenta y cinco grados. Los abundantes ejemplos de áticos y sobreáticos en casas situadas en los codiciados 
chaflanes, por la visibilidad que les da su amplia perspectiva, suelen resultar muy discordantes.

El edificio sito en paseo de Gràcia, 45, al que se añadieron dos plantas más ático y sobreático, es un ejemplo muy significativo y doblemente molesto porque vemos como este remonte dificulta la perspectiva de la Casa Batlló, al superarla en altura, oprimiendo su medianera derecha, y el ático y el sobreático añadidos completan el desacorde morfológico con su paradigmático entorno (figura 8). La Casa Batlló, construida en 1877 por Emilio Sala, fue reformada por Antonio Gaudí, entre 1904 y 1906, que le dio el llamativo carácter modernista actual, visible tanto en su fachada principal como en la posterior, que podemos admirar desde el patio. En 1969 fue declarada Monumento Histórico-Artístico de Carácter Nacional.

Otro ejemplo de remonte discordante con la morfología urbana lo encontramos en calle Provenza, 237, también haciendo chaflán. A este inmueble de diseño ecléctico, que en origen contaba con cinco plantas, le remontaron otras dos, más ático y sobreático. En principio se entiende que esta ampliación en altura se diseñó con la idea de que fuera armónica con la obra primigenia, ya que se prolongaron algunos paramentos verticales y sobre la segunda planta añadida, se colocó una balaustrada semejante a la del terrado original. Pero no es coherente con este planteamiento, utilizar carpintería de aluminio simple, que, además de desentonar grotescamente, refleja cegadora los rayos del sol. En referencia al ático y sobreático agregados, que analizamos en esta tipología, obviamente, están fuera de norma, fuera de la ordenanza específica, que manda retrasar la construcción a cuarenta y cinco grados, lo que da una imagen desorbitada al edificio (figura 9).

Figuras 8 y 9. Semiocultos: Áticos y sobreáticos
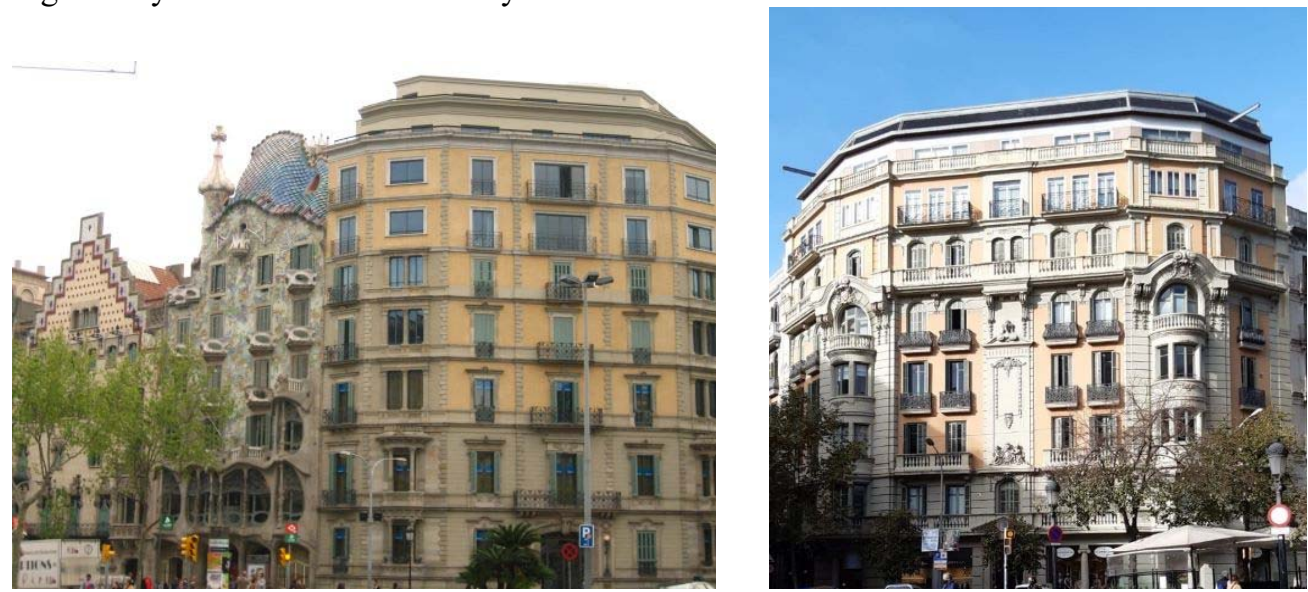

(*) Nota. Localización de los edificios. Figura 8: paseo de Gràcia, 45. Figura 9: calle Provenza, 237.

Fuente: Foto de los autores

De las 298 casas con remontes, hemos hallado 4, a las que se les ha añadido solo ático (un $1,6 \%$ ) y 71 con áticos y sobreáticos (un 23,8\%). Pero si a estos sumamos 
los áticos y sobreáticos añadidos sobre los remontes, que son 136 , vemos que se han edificado un total de 211.

\subsubsection{Simples}

Contrastando tanto con la libertad y pureza arquitectónica de la Casa Milá de Antonio Gaudí, como con el excesivo adorno constructivo de las fachadas de conocidos edificios del Quadrat d'Or, destinados al lucimiento de una exuberante burguesía local, encontramos unos remontes anodinos, de construcción pobre y simple, realizados sobre fincas correctamente diseñadas, cuyas fachadas sufren un perjuicio evidente. Fuera del perímetro que analizamos, es frecuente ver remontes con estas carencias, pero estos añadidos desentonan más, por estar llevados a cabo en vías de alto nivel estético y socioeconómico.

En calle Valencia, 282 (figura 10) y rambla de Catalunya, 96 (figura11), tenemos dos ejemplos. En ambos casos son fincas características de finales del siglo XIX y principios del XX, a las que se han aplicado remontes, de una planta a la primera y de dos a la segunda, sin ninguna preocupación estética, ya que ni los materiales utilizados ni el diseño demuestran interés por una solución en armonía o en contraste.

Figuras 10 y 11. Simples
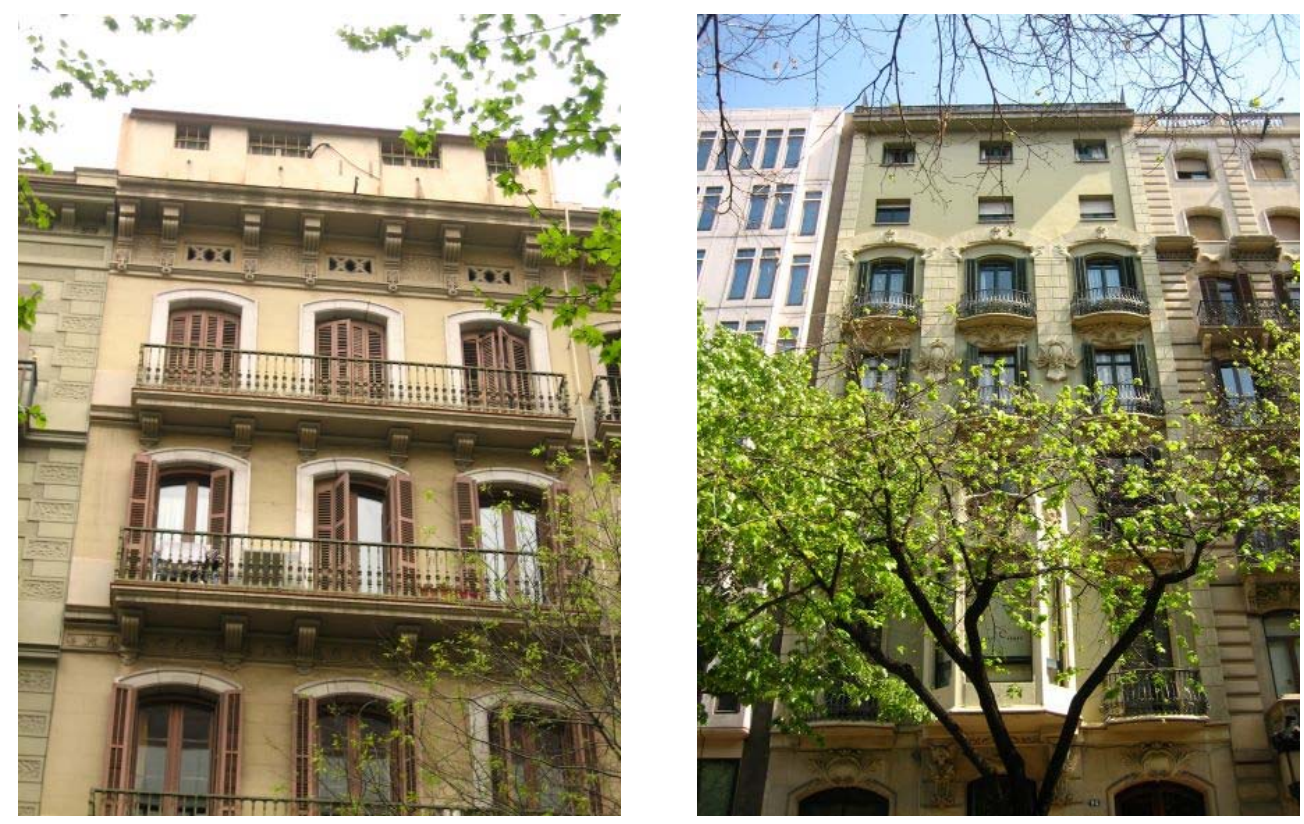

(*) Nota. Localización de los edificios. Figura 10: calle Valencia, 282. Figura 11: rambla de Catalunya.

Fuente: Foto de los autores 
Hemos encontrado 54 remontes constructivamente muy simples y desunidos a la fachada que amplían (el 18\%). Hay que señalar que, de estos, un 23,4\% poseen áticos o áticos y sobreáticos de acabados similares.

\subsubsection{Desacordes}

En el Quadrat d'Or encontramos un tipo de remontes que, por no tener relación armónica con la casa original, porque han prescindido del edificio que acrecientan, resulta estéticamente desacorde. Algunos simulan el color del revoque, pero otros prescinden de intentar una mínima coherencia en la fachada.

Tomemos como ejemplo el elegante edificio de Gran Vía, 646, de características eclécticas, que ostenta un gran mirador central y otros dos laterales en sendas plantas superiores, muy ornamentados, donde se ha añadido un triste cuerpo de dos plantas y ático, con alineaciones horizontales de ocho ventanas cada una, que desprecia la línea estilística de esta casa (figura 12).

A su vez, en paseo de Gracia, 102, en un edificio donde se ha hecho un remonte de dos plantas mas ático y sobreático, la preocupación por la armonía o por la búsqueda de una adaptación contrastada con la fachada, es manifiestamente inexistente (figura 13).

Podríamos entender que, en estos dos ejemplos, se ha planteado la ampliación como si se tratara de obra nueva.

Figuras 12 y 13 . Desacordes
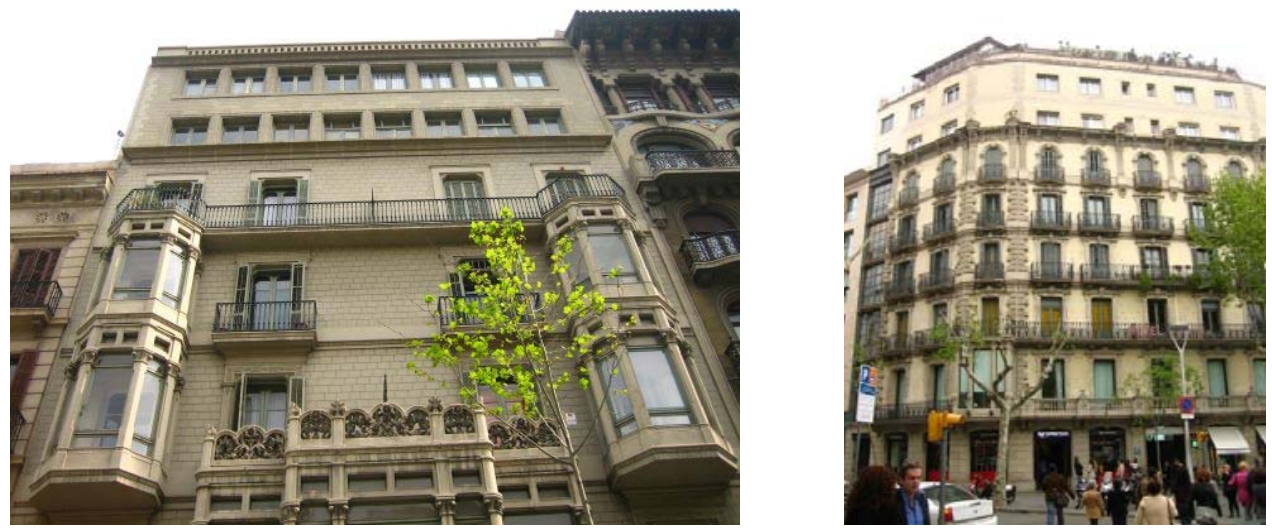

(*) Nota. Localización de los edificios. Figura 12: Gran Vía, 646. Figura 13: paseo de Gràcia, 102.

Fuente: Foto de los autores.

Con esta tipología contamos 98 casas, un 32\% del total observado en esta investigación. 


\subsubsection{En voladizo}

Por sus características volumétricas, este modelo de remonte supera al de la tipología que denominamos desacordes en lo exagerado de su morfología, resultando extravagante a la vista de cualquier ciudadano. Estos desafueros son producto de los excesos especulativos del capital inmobiliario que lógicamente lo utiliza para su reproducción, haciendo caso omiso de la Ordenanza de Manzana de 1891, que fue dictada exclusivamente para el Ensanche de Barcelona, y mediante la que se otorgaba amplia libertad para la elaboración de las fachadas, pero naturalmente, con la intención de enriquecer la plasticidad de estas.

El artículo 124 de esta ordenanza pedía que no se hicieran obras extravagantes o ridículas. Posteriormente, las Ordenanzas Municipales de 1958, de nuevo dicen en su punto 2 que se evitarán siempre efectos discordantes, y en su punto 3 que se denegará licencia a los proyectos extravagantes, ridículos o impropios. Esta preocupación también se manifiesta en la Normativa de Texto Refundido de la Ordenanza de Rehabilitación y Mejora del Ensanche, en su artículo 23.

Además, las casas remontadas que analizamos en esta tipología, están contenidas en el Plan Especial de Protección del Patrimonio Arquitectónico de la Ciudad de Barcelona e incluidas en el Catálogo de Protección Arquitectónica Histórica y Paisajística de los Establecimientos Emblemáticos de la Ciudad de Barcelona.

El primer caso que valoramos, es una finca sita en calle Aragó, 360, de estilo Modernista construida en 1900 y que mantiene los dinteles de los balcones del inmueble original decorados con relieves acordes con este estilo. Un mérito especial lo muestra el zócalo del vestíbulo general, realizado con mosaico cerámico esmaltado de estilo ecléctico, con decoración floral en relieve (Servei d'Arqueologia de Barcelona), razón por la que está inventariado por el Servei d'Arqueología de Barcelona. El motivo de la inclusión de esta casa es que fue truncada para construir un remonte en agresivo voladizo, aprovechando al máximo la superficie edificable que las incongruentes normativas municipales conceden (figura 14).

Con características similares, en el edificio de la calle Pau Claris, 77, una finca neoclásica tardía con un característico portón de madera, se han levantado tres plantas desiguales, con un voladizo donde únicamente los ejes de los huecos de las ventanas de ambos extremos del remonte coinciden con la obra original y el resto de las aberturas son desiguales y no observan normas estéticas (figura 15).

El clásico y elegante edificio de rambla de Catalunya, 127 es de configuración diferente. Con una hermosa puerta de fundición, realizada en arco de medio punto, con imponentes miradores centrales en las dos primeras plantas, y balcones en forma de segmentos circulares, ha sufrido un remonte en voladizo disforme de dos plantas con sendas filas de ventanucos, desacordes con el alzado originario (figura 16).

Mostramos como último ejemplo de esta tipología, la casa número 93 de la calle Bailén, que hace chaflán con calle Aragó, por ser ciertamente el caso más descomedido con las características del Quadrat d'Or. La fachada de este edificio de inspiración neoclásica, gozaba de una gran armonía, hasta que sobre los frontones de los balcones de su última planta se "perpetró" un tremendo remonte en voladizo de dos plantas, 
mas ático y sobreático, con un incoherente diseño funcional que, por su desconsiderada y especulativa morfología llama poderosamente la atención (figura 17).

Figuras 14, 15, 16 y 17. En voladizo.
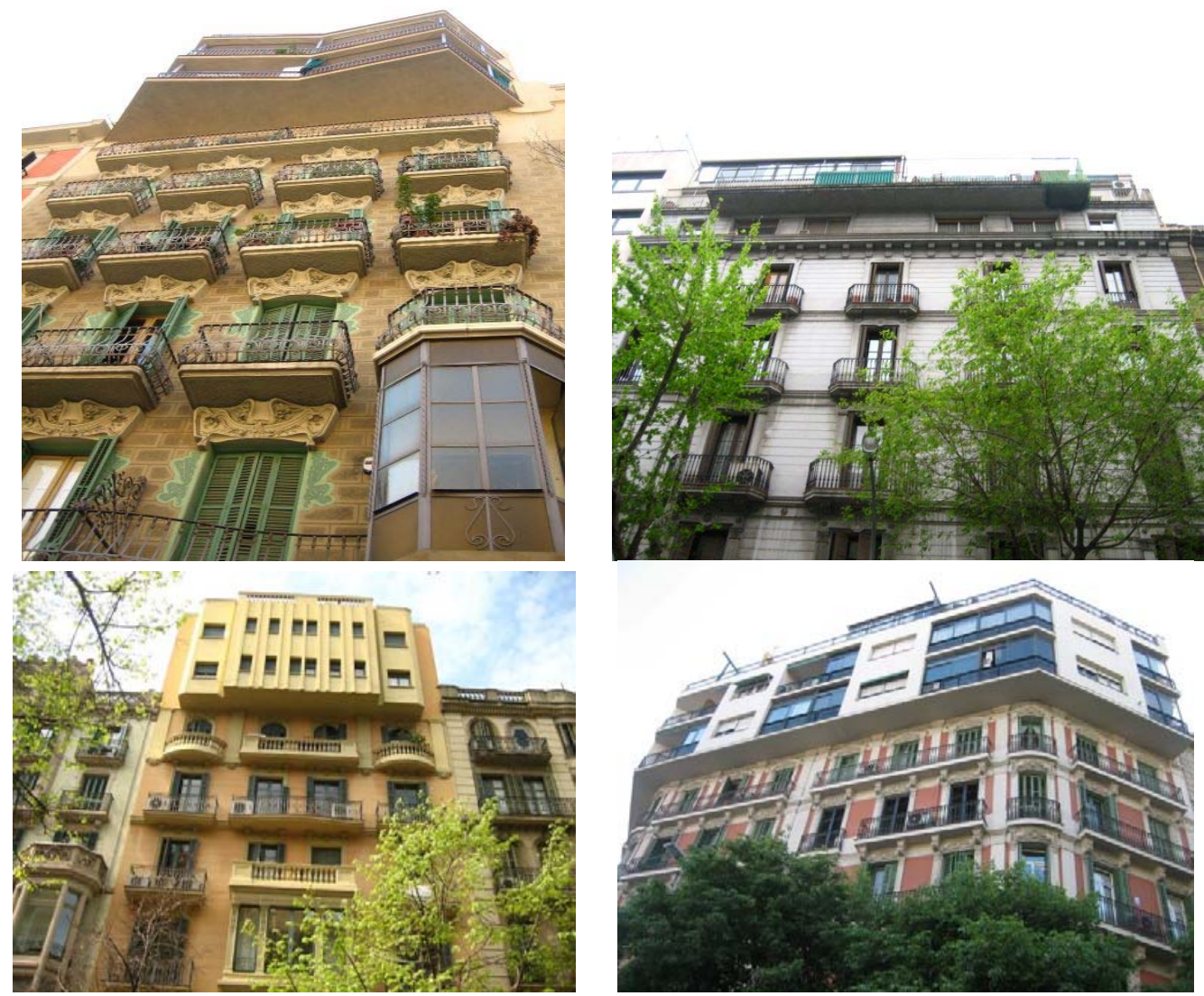

(*) Nota. Localización de los edificios. Figura 14: calle Aragó, 360. Figura 15: calle Pau Claris, 77. Figura 16: rambla de Catalunya, 127. Figura 17: calle Bailén, 93.

Fuente: Foto de los autores

Hemos encontrado 32 remontes en voladizo, el 10,7\% del total observado, y la mayoría, un 7,3\% del total, posee ático y sobreático. 


\subsubsection{Elementos superpuestos}

En el último grupo de alteraciones en las fachadas del Quadrat d'Or situamos los añadidos producidos en los terrados de varias casas de forma desordenada, sin obedecer las ordenanzas que permiten construir cajas de escalera, torres, palomares, departamentos de servicio etc. en la mitad del fondo edificado, paralelamente al muro de fachada.

Se hacen chamizos junto a la fachada o muy próximos a ella, de forma variable y con acabados muy deficientes. Estas construcciones no abundan, pero cuando aparecen a la vista, la impresión general es grotesca, como se observa en calle Bailen, 25 (figura 18).

Existe también el caso sorprendente de la casa de cinco plantas, ubicada en paseo de Gracia, 71 (figura 19), donde se observa, superpuesto en el terrado, un antiguo observatorio astronómico. Nos dicen que fue una autoconstrucción llevada a cabo por estudiantes, miembros de la sociedad astronómica Aster. Cuentan que, con un aparato de radio, grabaron desde allí la señal del Sputnik, el primer satélite soviético lanzado al espacio. Estuvo funcionando desde 1953 hasta 2004, cuando fue abandonado, y así sigue.

En el ámbito del Quadrat d'Or observamos la presencia de 5 chamizos: dos en calle Aragó, uno en calle Bailén, otro en calle Casp y un último en paseo de Gracia. Añadimos, como ilustración de esta tipología, dos de ellos.

Figuras 18 y 19. Elementos sobrepuestos

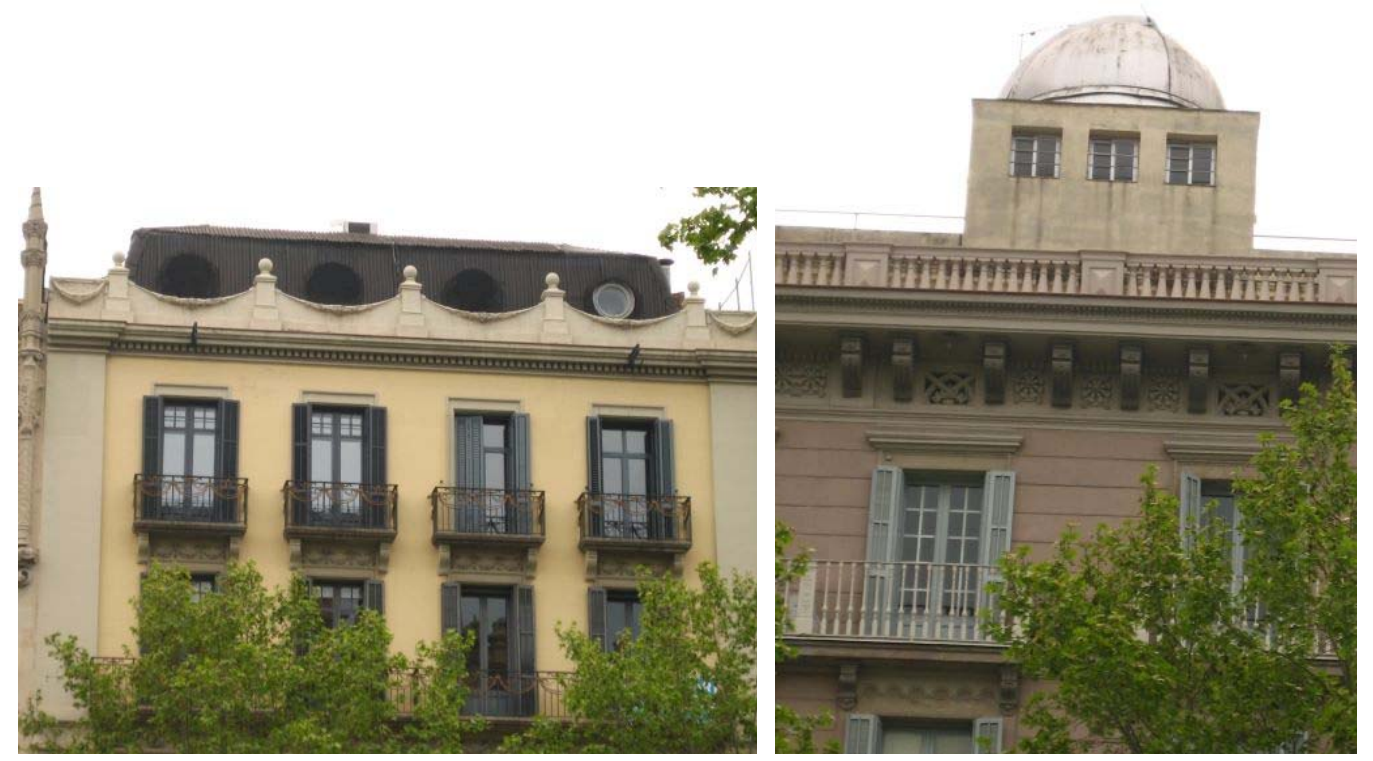

(*) Nota. Localización de los edificios. Figura 18: calle Bailén, 25. Figura 19: paseo de Gràcia, 71.

Fuente: Foto de los autores. 

dos.

Estos elementos representan el $1,6 \%$ del total contabilizado de remontes y añadi-

Este análisis tiene que ver con lo que Francesc Muñoz (2009) denomina un Eixample como un tablero de juego en el que la ciudad y su urbanismo establecen un diálogo ininterrumpido con el Plan y sus resultados. Lo que nos lleva a concordar con Horacio Capel, cuando refriere que,

Tal vez tendrían que tener más en cuenta (los arquitectos) la actitud del segundo arquitecto de la plaza de la Annunziata de Florencia, iniciada por Brunelleschi, un ejemplo bien conocido y valorado en libros que son habitualmente usados en las Escuelas de Arquitectura; en aquel caso Sangallo supo "dominar su impulso hacia la autoexpresión” y siguió, en cambio, el modelo del edificio construido por Brunelleschi, que tenía noventa años de antigüedad, contribuyendo a crear con ello un espacio inolvidable (Capel, 2005).

Los resultados obtenidos sobre la muestra total, concuerdan con estas afirmaciones. Pensamos que, si a modo de balanza, pusiéramos en un lado los remontes y añadidos que encajan en las tipologías: a) realizados armonizando con la obra original (4\%) y b) contrastando mediante diseño y estructuras funcionales $(8,3 \%)$, que valoramos positivamente, vemos que representan solo un $12,3 \%$ del total; mientras en el otro, la suma de los añadidos y remontes de características inadecuadas, mal compuestos o de mal gusto, impropios de su ubicación, que representan una gran mayoría, el 87,7 \% del total de edificios estudiados, el fiel de esta balanza nos sonrojaría, porque la morfología de una ciudad habla del carácter de sus habitantes. En palabras de Aristóteles "no depende solo del domicilio el ser ciudadano".

\section{Conclusión}

Al realizar este trabajo, nuestra intención ha sido efectuar un estudio que enfatice en la importancia de la armonía urbana, puesto que el Ensanche de Cerdá confiere a la ciudad un destacado sentido de orden, de funcionalidad, de humanidad y de belleza. Nos acogemos a este último concepto de belleza, porque este Ensanche contiene una importante proporción de inmuebles significativos, claves en la arquitectura barcelonesa, y como todas las planificaciones urbanas, cuenta con admiradores y detractores.

Aunque los edificios presentan un interés singular, su valor histórico-artístico es mucho más relevante si el conjunto de ellos mantiene unas características de cierta armonía y coherencia estética porque refleja las preocupaciones estéticas de un determinado período. Por esto, nos ha sorprendido constatar que todas las casas remontadas o añadidas que hemos estudiado -tanto si estas ampliaciones se han hecho respetando el edificio preexistente, como cuando no ha sido así-, están contenidas en el Plan Especial de Protección del Patrimonio Arquitectónico de la Ciudad de 
Barcelona e incluidas en el Catálogo de Protección Arquitectónica Histórica y Paisajística de los Establecimientos Emblemáticos de la Ciudad de Barcelona.

En la construcción original de la mayoría de los edificios, participaron excelentes arquitectos que respetando las ordenanzas urbanísticas vigentes se lucieron con el diseño de obras con características del Neoclasicismo, del Eclecticismo posterior, del Modernismo y del minusvalorado Noucentisme en las primeras décadas del siglo XX, estilos a los que posteriormente se sumaron corrientes funcionalistas.

Sin embargo, aprovechando las "Ordenanzas Congestivas", los propietarios para obtener plusvalías, muchas veces sin preocuparse de las anomalías formales que ocasionan al propio edificio y al conjunto urbanístico, han impulsado los remontes y añadidos para "subir" la edificación hasta el máximo permitido, que suele oscilar entre una y tres plantas. Merecen también mención los áticos y sobreáticos que se añaden cuando la altura reguladora máxima no puede superarse, construyendo dos plantas más, retrasando, o no, las fachadas de estas ampliaciones.

Como hemos constatado, la picaresca y la corrupción han hecho de forma reiterada que el resultando sea una considerable alteración morfológica. Por un lado, el poder municipal, desde el principio y a lo largo de más de un siglo fue de tendencias tan antagónicas que producía leyes y ordenanzas contradictorias. También las leyes que han planificado y ordenado el Ensanche de Barcelona se han aplicado con laxitud, permitiendo la manipulación y la especulación de la iniciativa privada.

Por otro lado, arquitectos de diferentes tendencias y estilos, fueron y son hoy, los encargados de dar forma, o sea de la estética. Estos tienen la función de proyectar las ampliaciones de las casas y de controlar la realización material de estas (dirección de la obra), por esto son los responsables formales de muchos desaguisados producidos. Claro que los proyectos, para hacerse realidad pasan por el control del Colegio de Arquitectos de Cataluña, que ha de visarlos y autorizarlos.

$\mathrm{Y}$ al fin, fundamentalmente la iniciativa privada -contemplada en las normas de ordenación del ensanche- que materializa la urbanización y la edificación, es la responsable última de los remontes y añadidos, tanto cuando actúa con respeto e imaginación, como cuando "ignora" o desprecia los criterios formales, actitud esta, que se caracteriza por una impresionante desidia y un evidente interés especulativo.

\section{Bibliografía}

Aibar Puentes, E. (1995): Urbanismo y estudios sociohistóricos de la tecnología: el caso del ensanche de Barcelona. Llull: Revista de la Sociedad Española de la Historia de las Ciencias y de las Técnicas, 18, 5-34 <https://dialnet.unirioja.es/ejemplar/6783>.

Alibes, J. M., Campo, M., Giralt, E., Huertas Claveria, J. M., Pradas, R., Tarrago, S. (1973): La Barcelona de Porcioles. CAU: Construcción/ Arquitectura/ Urbanismo. Publicación del Colegio oficial de Aparejadores y Arquitectos Técnicos de Cataluña., 21.

Ayuntamiento de Barcelona (1891): Ordenanzas Municipales de la ciudad de Barcelona. Promulgadas como suplemento al Boletín Oficial de esta Provincia: 19 de marzo. Imprenta de Federico Sánchez <https://bcnroc.ajuntament.barcelona.cat/jspui/handle/11703/96467>. 
Ayuntamiento de Barcelona (1947): Ordenanzas Municipales de la ciudad de Barcelona. Barcelona, Gráficas Casulleras <http://hdl.handle.net/11703/96471>.

Ayuntamiento de Barcelona (1958): Ordenanzas Municipales de Edificación. Barcelona, Casa Provincial de Caridad/Imprenta-Escuela. Título Primero $<$ https://bcnroc.ajuntament.barcelona.cat/jspui/bitstream/11703/96484/3/7216.pdf $>$.

Ayuntamiento de Barcelona (1958): Ordenanzas Municipales de Edificación. Barcelona, Casa Provincial de Caridad/Imprenta-Escuela. Título Cuarto $<$ https://bcnroc.ajuntament.barcelona.cat/jspui/bitstream/11703/96479/6/7155.pdf $>$.

Busquets, J. (2004): Barcelona: La construcción urbanística de una ciudad compacta. Colección La Estrella Polar, 43. Barcelona, Serbal.

Busquets, Joan. (2009): Un proyecto innovador convertido en gran realidad. Barcelona Metrópolis. La razón en la ciudad: el Plan Cerdà (Cuaderno Central). Barcelona, $\begin{array}{llll}\text { Ayuntamiento de } & \text { Barcelona, } & 71-87\end{array}$ $<$ http://www.anycerda.org/congres/documentacio/postmetropolis/docs/A/A21.pdf $>$.

Capel, H. (2005): El modelo Barcelona: un examen crítico. Barcelona, Serbal.

Cañellas, C., Toran, R. (1990): Heterogeneïtat urbana, desplaçaments geogràfics i canvis polítics. En Garcia Espuche, A. (Dir.): La formació de l'Eixample de Barcelona. Fundació Caixa de Catalunya y Col·legi d'Arquitectes de Catalunya, 191- 202.

$\begin{array}{llll}\text { Catálogo del Patrimonio Arquitectonico } & \end{array}$ $<$ https://ajuntament.barcelona.cat/ecologiaurbana/es/servicios/la-ciudadfunciona/urbanismo-y-gestion-del-territorio/informacion-urbanistica/buscador-delpatrimonio-arquitectonico $>$.

García Ávila, M. B. (2005): Arte-artesanía, interacción histórica. Biblio 3W, Revista Bibliográfica de Geografía y Ciencias Sociales, 10 (599) <http://www.ub.es/geocrit/b3w599.htm>.

García Espuche, A. (2002): El Quadrat d'Or. Centro de Barcelona modernista. Barcelona, Ajuntament de Barcelona y Lunwerg Editores.

Guàrdia Bassols, M. (2009): La ciudad del XIX y el pensamiento moderno. En La razón en la ciudad: el Plan Cerdà. Barcelona Metrópolis. Barcelona, Ayuntamiento de Barcelona, 76, 58-61 <http://www.anycerda.org/congres/documentacio/postmetropolis/docs/A/A21.pdf>.

Luque, A. (2020): La manualidad se ha marginado completamente en el arte. Entrevista a Oscar Tusquets, Colectivo Mediterráneo Sur $<$ https://msur.es/2020/03/18/oscar-tusquets/>.

Magrinyà, F. (1999): Las influencias recibidas y proyectadas por Cerdà. Ciudad y Territorio. Estudios Territoriales, 31 (119-120), 95-117.

Magrinyà, F. (2009): El ensanche y la reforma de Ildefons Cerdà como instrumento urbanístico de referencia en la modernización urbana de Barcelona. Scripta Nova. Revista Electrónica de Geografía y Ciencias Sociales, 13, 296 (3) <http://www.ub.es/geocrit/sn/sn296/sn-296-3.htm>.

Miró, Asha (2017): La Barcelona de Lluis Permanyer. "La Casa Milà es la casa más admirada y criticada de Barcelona", dice el veterano el veterano periodista. Metrópoli. Entrevista, 02/12/2017<https://www.metropoliabierta.com/quien-hace-barcelona/personas/barcelonalluis-permanyer_3939_102.html $>$. 
Muñoz, F. (2009): Pasado y futuro de la Barcelona territorio. La razón en la ciudad: el Plan Cerdà. Barcelona Metrópolis, Barcelona, Ayuntamiento de Barcelona, 76, 46-47 $<$ http://www.anycerda.org/congres/documentacio/postmetropolis/docs/A/A21.pdf $>$.

Normativa Urbanística Metropolitana.

(2004): $<$ http://www3.amb.cat/normaurb2004/Docs/normes.htm>.

Permanyer L. (2001): La Diagonal, historia de una ambición: Un siglo en Diagonal. Barcelona Metrópolis Mediterrània. Barcelona, Ayuntamiento de Barcelona, 56 $<$ http://www.bcn.cat/publicacions/catala/bmm/ebmm56/bmm56_32.htm>.

Provincia de Barcelona (2002): Butlletí Oficial de la Provincia de Barcelona, 297, 12/12.

Rebés Solé, J. E. (2005): Can Serra y la Diputación de Barcelona. El País, 02/05/2005 $<$ https://elpais.com/diario/2005/05/02/catalunya/1114996050_850215.html>

Rueda, S. (2016): La supermanzana, nueva célula urbana para la construcción de un nuevo modelo funcional urbanístico de Barcelona. $<$ http://www.bcnecologia.es/sites/default/files/proyectos/la_supermanzana_nueva_celula_p oblenou_salvador_rueda.pdf $>$.

Sabaté, J. (2009): Los primeros constructores o la fortuna del Eixample. La razón en la ciudad: el Plan Cerdà. Barcelona Metrópolis. Barcelona, Ayuntamiento de Barcelona, 76, 67-71 $<$ http://www.anycerda.org/congres/documentacio/postmetropolis/docs/A/A21.pdf $>$.

Servei d'Arqueologia de Barcelona $<$ https://ajuntament.barcelona.cat/arqueologiabarcelona/mosaics/mosaic/carrer-darago360/>.

Tafunell i Samboia, X. (1989): La construcción residencial barcelonesa y la economía internacional. Una interpretación sobre las fluctuaciones de la industria de la vivienda en Barcelona durante la segunda mitad del siglo XIX. Revista de História Económica, 7 (2), 389-437 <https://dialnet.unirioja.es/servlet/articulo?codigo=97496>.

Tafunell i Sambola, X. (1994): La construcció de la Barcelona moderna. La industria de l'habitatge entre 1854 i 1897. Barcelona, Ajuntament de Barcelona.

Tatjer, M. (1996): La construcció residencial a la Barcelona de la segona meitat del segles XIX. Comentaris al llibre de X. Tafunell. Biblio 3W. Revista Bibliográfica de Geografía y Ciencias Sociales, 2, <http://www.ub.edu/geocrit/b3w-2.htm>.

Tatjer, M. (2003): La vivienda popular en el Ensanche de Barcelona. Scripta Nova. Revista Electrónica de Geografía y Ciencias Sociales, 7, 146(021) $<$ http://www.ub.es/geocrit/sn/sn-146(021).htm>.

Tatjer, M. (2009): El Plan Cerdà y el porciolismo. Barcelona Metrópolis. La razón en la ciudad: el Plan Cerdà. Barcelona, Ayuntamiento de Barcelona, 76, 73-79 $<$ http://www.anycerda.org/congres/documentacio/postmetropolis/docs/A/A21.pdf $>$.

Zaar, M. H. (2017): El derecho a la vivienda en el contexto del Plan Especial Urbanístico de Alojamientos Turísticos (PEUAT) de Barcelona y de sus planes antecesores. Biblio 3W. Revista Bibliográfica de Geografía y Ciencias Sociales, 22, 1.210 $<$ http://www.ub.edu/geocrit/b3w-1210.pdf $>$.

Zaar, M. H. (2019): Gentrificación y turismo urbano. ¿Cómo se articulan? Ar@cne. Revista Electrónica de Recursos de Internet sobre Geografía y Ciencias Sociales, 23, 230 $<$ http://www.ub.edu/geocrit/aracne/aracne-230.pdf $>$. 